OPEN ACCESS

Edited by:

Douglas Frye,

University of Pennsylvania, United States

Reviewed by: Beth Oakley, King's College London, United Kingdom Pietro Spataro,

Mercatorum University, Italy

*Correspondence: Anna Maria Rosso rosso@unige.it

${ }^{\dagger}$ Present address: Arianna Riolfo,

Private Practice in Toirano, Italy

Specialty section:

This article was submitted to

Cognitive Science,

a section of the journal

Frontiers in Psychology

Received: 22 July 2020 Accepted: 16 November 2020 Published: 07 December 2020

Citation:

Rosso AM and Riolfo A (2020) $A$

Further Look at Reading the Mind in the Eyes-Child Version: Association

With Fluid Intelligence, Receptive

Language, and Intergenerational Transmission in Typically Developing School-Aged Children

Front. Psychol. 11:586065. doi: 10.3389/fpsyg.2020.586065

\section{A Further Look at Reading the Mind in the Eyes-Child Version: Association With Fluid Intelligence, Receptive Language, and Intergenerational Transmission in Typically Developing School-Aged Children}

\author{
Anna Maria Rosso* and Arianna Riolfo ${ }^{+}$ \\ Department of Education, University of Genoa, Genoa, Italy
}

A number of tasks have been developed to measure the affective theory of mind (ToM), nevertheless, recent studies found that different affective ToM tasks do not correlate with each other, suggesting that further studies on affective ToM and its measurement are needed. More in-depth knowledge of the tools that are available to assess affective ToM is needed to decide which should be used in research and in clinical practice, and how to interpret results. The current study focuses on the Reading the Mind in the Eyes Test (RMET) primarily to investigate in a sample of 112 children the currently unexplored relationships in middle childhood between performance on the RMET and fluid intelligence. Relationships with receptive vocabulary, age, and sex were also investigated. Moreover, because studying the family's influence on children mentalization could have important implications in developing prevention and treatment interventions, this study offers a novel contribution to the field by exploring the family's influence on children's RMET performance. Although significant positive correlations were found among RMET-C performance, fluid intelligence, and receptive language, regression analysis revealed that fluid intelligence was the only predictor. No family influence was found on children's RMET performance. On the whole, results from the current study offer some support to the hypothesis that RMET-C is not a "pure" ToM task, specifically the effect of fluid intelligence on RMET performance should be taken into account when RMET is used both in research and in the clinical setting.

Keywords: reading the mind in the eyes, receptive language, fluid intelligence, theory-of-mind, intergenerational transmission 


\section{INTRODUCTION}

Mentalization refers, in a broad sense, to the human ability to interpret one's own and others' behavior in terms of intentional mental states (e.g., desires, needs, feelings, and beliefs) (Allen, 2003; Fonagy and Target, 2005).

Over the last decades several tasks have been designed to evaluate mentalization, and an extensive body of studies has focused on its development in non-clinical samples and its impairment in clinical groups. As Luyten et al. (2019) stated, mentalizing has become over time an umbrella concept that overlaps with Theory of Mind (ToM), so that in literature mentalization and ToM are often used as interchangeable terms. At first, developmental studies focused largely on children's understanding of false belief (Wimmer and Perner, 1983), then research moved toward the investigation of emotion decoding (Baron-Cohen et al., 2001a), pragmatic language comprehension (Happé, 1994), and mental state talk (Bartsch and Wellman, 1995), while more recently studies have focused on children's reflective functioning in the context of close attachment relationships (Ensink et al., 2015).

A vast array of studies support the hypothesis that the construct of mentalization is a complex and multifaceted one (for a review, Fonagy and Bateman, 2019) that includes distinct components underpinned by different neural correlates (Schurz et al., 2014; for a review).

A number of instruments have been designed to assess mentalization in adults and in children, however, to date, it is not really clear which component(s) of mentalization each tool actually measures. Warnell and Redcay (2019) administered a diverse set of ToM tasks to three different sample groups, each of which contained children of the same age, and found that at any age, receiving high scores on one task did not predict performance on another task designed to assess the same underlying ability. In middle childhood, this study did not find any significant correlation between the scores obtained on the children's version of the Reading the Mind in the Eyes (RMETC; Baron-Cohen et al., 2001b), the Strange Stories (Happé, 1994), and the Faux Pas Task (Baron-Cohen et al., 1999). In addition, in middle childhood full-scale IQ was significantly related only to Strange Stories performance, suggesting that the association between ToM and intelligence should be investigated regarding each ToM component, rather than assumed regarding ToM as a unitary construct.

Some recent developmental studies on samples of preschool children (e.g., Lecce et al., 2015; Longobardi et al., 2017) offered support for a distinction between cognitive and affective ToMnamely the ability to attribute beliefs and/or intentions above and beyond the appearance vs. the ability to recognize and infer emotions and feelings.

In addition, Gallant et al. (2020) found that different affective ToM tasks did not correlate with each other in a sample of preschool children, supporting the hypothesis that diverse instruments measure distinct facets of affective ToM, consequently they suggested that further studies on affective ToM and its measurement are needed.
The current study aims primarily to investigate in a sample of school-aged children the currently unexplored relationship between performance on the RMET - a widely used affective ToM task-and fluid intelligence. Relationships among RMET performance, receptive vocabulary, age, and sex were also investigated.

Baron-Cohen et al. (1997, 2001a) developed the adult version of the RMET both to measure sensitive to subtle dysfunction in the domain of social cognition in adults with a diagnosis of autism or Asperger syndrome, and for use with adults of normal intelligence. RMET consists of 36 photographs of the eye region of the face of different actors and actresses. At the four corners of each photo there are four words (the target word and its three foils), the subject is simply required to choose the correct term.

The test was conceived as a measure of the individuals' ability to put themselves into the mind of the other person by tuning into their mental state. Consequently, Baron-Cohen et al. (2001a) defined the test as an advanced theory of mind task which requires having a mental state language and, at a quick and automatic level, matching the eyes in each photo to eye region expressions stored in one's memory as seen in the context of a particular mental state, and to choose the word the eyes in the photo most closely match. Baron-Cohen et al. (2001a) specified that RMET only implies the first stage of theory of mind, namely the attribution of the relevant mental state, whereas it does not include the second stage consisting of inferring the content of that mental state (e.g., in the case sadness was identified as the mental state, participants were not required to infer the reason why). The test includes a control task consisting of showing the same photographs again and asking the participant to determine the gender of the person based on his/her eyes. This control task, named Gender Recognition task, implies a non-mentalistic social cognition from the eyes as well as attention to the stimuli.

The final version of the RMET was able to detect meaningful individual differences with normal performance significantly below ceiling. In the original study no effect of general intelligence was observed in the non-clinical sample with regard to RMET performance, while a trend toward a female advantage was found. On the contrary, the most recent meta-analyses (Baker et al., 2014; Peñuelas-Calvo et al., 2019) found that intelligence played a significant role in adults' non-clinical performance on the RMET and that verbal and performance abilities equally contribute to this relationship. The better performance by females on RMET was confirmed by another meta-analysis (Kirkland et al., 2013). Recently, Baron-Cohen et al. (2015) too, in an extensive study, found that females outperformed males in non-clinical samples, while no sex difference was found in individuals with autism.

A child version (RMET-C; Baron-Cohen et al., 2001b), conceptually derived from the adult version, consists of 28 photographs of the eye region of female and male adult actors. Like the adult version, each illustration is accompanied by four words that refer to mental states (e.g. "hate," "surprise," "cross," kind"). The child is asked to point to the one that best represents what that person feels or thinks. The Gender Recognition task may be used as a control test, like in the adult version. 
Although the test has been very widely used, especially in the adult version, data regarding psychometric properties are rarely reported and are controversial, especially with regard to internal consistency that was found to be low in four studies (Voracek and Dressler, 2006; Harkness et al., 2010; Müller and Gmünder, 2014; Hayward and Homer, 2017), and minimally acceptable or acceptable in five other studies (Serafin and Surian, 2004; Dehning et al., 2012; Vellante et al., 2013; Girli, 2014; Vogindroukas et al., 2014). To our knowledge, only four studies have investigated internal coherence in the children's version (Girli, 2014; Müller and Gmünder, 2014; Vogindroukas et al., 2014; Hayward and Homer, 2017), and no studies have ever been conducted on an Italian sample. Test-retest stability was found to be acceptable for both the adult (Vellante et al., 2013) and the child version (Hallerbäck et al., 2009). Some studies confirmed the single factor structure assumed by BaronCohen et al. (2001a) both in the adult (Vellante et al., 2013) and in the child version (Carey and Cassels, 2013), while Olderbak et al. (2015) did not find a single-factor solution in the adult version.

RMET-C does not require reasoning about mental states but only recognizing them, thus it may be primarily considered a measure of affective mentalizing, mainly focused on emotion recognition (Oakley et al., 2016). Most studies (Rutherford et al., 2012; Ha et al., 2013; Fossati et al., 2014; Gallant et al., 2020) described RMET-C as a measure of affective ToM assessing the ability to understand the feeling of mental states. In addition, some studies (Lawrence et al., 2004; Carroll and Yung, 2006) found that it correlated with measures of empathy.

Although the child version of the RMET was used in several studies to compare ToM abilities in clinical and non-clinical samples, to our knowledge, no study has specifically aimed to investigate its relationship with verbal ability and non-verbal intelligence, nor with sex, age or family background.

Some studies reported data concerning the relationship between RMET-C performance and intelligence in typically developing school-aged children. Furthermore, these studies used different intelligence measures, making it hard to compare results. Some studies did not report a significant effect of intelligence on RMET-C performance (Sharp, 2008; Mary et al., 2016; Stevens et al., 2017), while Baribeau et al. (2015) found a significant effect, and Warnell and Redcay (2019) reported a trend toward statistical significance. Only two studies (Ibanez et al., 2013; Levy and Milgram, 2016) investigated the relationship between fluid intelligence and RMET-C performance, and reported a significant association.

Regarding sex, in children samples findings were contradictory in the few studies reporting data. A small effect of sex on RMET-C performance was found in two studies (Chapman et al., 2006; Baribeau et al., 2015), but no effect was reported in a more recent study (Warnell and Redcay, 2019).

Concerning the effect of age on RMET-C, results were inconsistent as well: some studies found a significant, positive correlation (Chapman et al., 2006; Baribeau et al., 2015; Durdiaková et al., 2015; Misailidi, 2018; Warnell and Redcay, 2019), whereas others did not (Sharp, 2008; Peterson et al., 2015; Hayward and Homer, 2017; Stevens et al., 2017).
To our knowledge, no previous study focused on the family's influence on children's RMET performance by investigating the effect of parents' education or the presence of older siblings, although parental level of education and the presence of older siblings were extensively taken into account when investigating their influences on children's ToM development, which resulted in mixed results (for a review, Hughes and Devine, 2017).

Concerning the intergenerational transmission of affective ToM, to our knowledge, only one study (Lecciso et al., 2013) has been conducted administering RMET both to mothers and children in a small sample of deaf and hearing children. However, they computed and reported a composite ToM score calculated from different ToM tasks, including RMET. Findings from this study showed that the maternal composite ToM index predicted the same ToM index in deaf children, but not in hearing children.

Two other studies investigated parental influences on children's ToM using RMET. Sabbagh and Seamans (2008) focused on intergenerational transmission of theory of mind skills in a typically developing population and found that parental performance on RMET correlated with the children's performance on a scaled battery of theory of mind tasks (not including RMET) in a sample of 46 children aged 3 and their parents (43 mothers and 3 fathers). Ragsdale and Foley (2011) studied maternal and paternal influences on RMET scores in an adult sample using correlations between pairs of full, maternal and paternal siblings and concluded that there was a maternal influence on RMET performance, although it remained unclear how much of this influence was genetic and how much was environmental.

Given the absence of previous studies on the family influence on children's RMET performance, and because studying the family's influence on children mentalization could have important implications in developing prevention and treatment interventions, this study aims to offer a novel contribution by investigating the effect of parents' education, the presence of older siblings, and of parental performance on RMET.

Because of the inconsistency of the findings from previous studies, the present study was exploratory regarding the effect of sex, age, and intelligence on RMET children's performance. Concerning intelligence, we decided to specifically investigate the effect of verbal ability and the effect of fluid intelligence using two measures designed to assess receptive vocabulary and abstract reasoning through perceptual stimuli.

Regarding the investigation of the relationship between parents' and children's performance on RMET, our study was also exploratory because, to our knowledge, this is the first study aimed at investigating the intergenerational transmission of affective ToM by assessing RMET performance both in children and in their parents.

\section{MATERIALS AND METHODS}

\section{Participants}

One hundred-twelve mothers $(M$ age $=40.77$ years $\pm 4.43 ; M$ education $=12.53$ years \pm 3.08$)$, 42 fathers $(M$ age $=43.73$ years $\pm 5.19 ; M$ education $=11.78$ years \pm 3.49$)$, and their children $(55$ 
males and 57 females, aged $77-139$ months $(M=108.02 \pm 17.13)$ agreed to participate in the study.

Participants were from intact, mostly working class families. Regarding education, only 11 mothers $(9.8 \%)$ and 11 fathers (9.8\%) had obtained a university degree, while 42 mothers (37.5\%) and 55 fathers (49.1\%) had received an education below the high school level. In this sample, the level of education was lower than the Italian average.

Participation was voluntary and no fee or other incentive was provided for taking part in the study.

None of the participants suffered from psychiatric or neurological illness or severe sensory impairment, none of the children had special educational needs, as reported by the family pediatricians.

\section{Measures}

\section{Affective ToM}

The RMET was administered to mothers and fathers to assess affective ToM. The Italian version (Vellante et al., 2013) showed acceptable internal consistency (Cronbach's alpha 0.605) and good test-retest stability ( $\mathrm{ICC}=0.833$ ). One point is assigned to each correct answer, 0 for the wrong or not given answer. The sum of the correct answers, ranging from 0 to 36 , was the score used in the current study. The control task Gender Recognition test was also administered to mothers and fathers to control the effect of non-mentalistic social intelligence, as suggested by Baron-Cohen et al. (2001a).

The Italian version (Liverta Sempio et al., 2003) of the RMETC was used to assess affective ToM in the children. As per administration guidelines, during the task participants could ask the examiner questions and look up a glossary available to them if they needed a better understanding of the words in the test. One point is assigned to each correct answer, 0 for the wrong or not given answer. The sum of the correct answers, ranging from 0 to 28 , was the score used in the current study.

The control task Gender Recognition test was administered to the children as well.

\section{Receptive Language}

The standardized Italian version (Stella et al., 2000) of the Peabody Picture Vocabulary Test-Revised (PPVT-R; Dunn and Dunn, 1981) was used to assess children's receptive vocabulary. PPVT-R consists of 180 cards, each of them presenting four drawings. The child was asked to point to the picture corresponding to the word pronounced by the examiner, and the item was scored 1 point or 0 points if it matched the picture or not, respectively. The examiner stops the test when the child gives eight wrong out of eight consecutive answers.

The task does not involve immediate memory or recall component. Raw scores were used and analyses were performed controlling for age.

\section{Fluid Intelligence}

The standardized Italian version (Belacchi et al., 2008) of the Raven's Progressive Matrices (CPM; Raven et al., 1998) was used to assess fluid intelligence. It is a non-verbal test of analytic reasoning designed for children aged five to eleven, consisting of
36 items over three sets (A, Ab, B), each including 12 items with increasing difficulty. All items have a missing segment with six possible choices for completion. Children were asked to select the one fitting the drawing best. Raw scores were used and analyses were performed controlling for age.

\section{Procedure}

The study was presented to three family pediatricians who agreed to collaborate in the research by asking parents and their children (only those not suffering from psychiatric or neurological illness or severe sensory impairment, or having special educational needs) for consent to be contacted by researchers. $70 \%$ of parents agreed to be contacted, after which a researcher called them to schedule a meeting. All the families agreed to allow their children to participate. All the mothers agreed to participate as well, while only 42 fathers were willing to be administered RMET. All the children gave their assent. During the first meeting with parents and children, the study was further illustrated, then the RMET was administered to the parents and two subsequent appointments were scheduled to meet the child and to administer in counterbalanced order the RMET-C, the Raven Colored Progressive Matrices, and the PPVT-R. All the participants were met individually at the family pediatricians' office. As per administration guidelines, no time limit was given to complete the tasks, and a break of about 10 min between one task and the next was offered to the children. Each of the two sessions with the children lasted no more than $45 \mathrm{~min}$, and on average, 7-10 days went by between appointments.

Ethical approval for this study was not required in accordance with local legislation and national guidelines. Written informed consent to participate in this study was provided by the participants' legal guardian/next of kin.

\section{RESULTS}

Preliminary analyses of the data indicated that the study variables, except paternal education and scores on Gender Recognition task, were normally distributed with skewness and kurtosis values falling within the accepted range of \pm 2 (George and Mallery, 2010), thus appropriate for parametric statistical tests. Descriptive statistics are reported in Table 1.

Only 54 mothers, 12 fathers, and 34 children performed at ceiling on the Gender Recognition test, however no significant association was found between RMET and control task for mothers $(r h o=0.045, p=0.645)$, fathers ( $r h o=0.214, p=$ $0.174)$, or children ( $r h o=0.132 ; p=0.166)$. As shown in Table 1, mean values on control task were near to ceiling.

RMET-C internal consistency, as measured by Cronbach's alpha, was 0.593 .

A $t$-test was performed to analyze the effect of sex on the variables of interest. No significant effect of sex was found on children's age, scores on RMET-C, PPVT-R, or CPM ( $p$ s ranging from 0.178 to 0.959 ).

Since a significant correlation $(r=0.391 ; p<0.0001)$ was found between age and children's performance on RMET, the effect of sex was investigated again by performing an analysis of covariance with age as the covariate. This analysis confirmed that 
TABLE 1 | Descriptive statistics: Age, Reading the Mind in the Eyes Test, Gender Recognition task, Education, 4 Peabody Picture Vocabulary Test, Raven Progressive Matrices.

\begin{tabular}{|c|c|c|c|c|c|c|}
\hline \multirow[b]{2}{*}{ Variable } & \multicolumn{2}{|c|}{$\begin{array}{l}\text { Mothers } \\
(N=112)\end{array}$} & \multicolumn{2}{|c|}{$\begin{array}{c}\text { Fathers ( } N \\
=42)\end{array}$} & \multicolumn{2}{|c|}{$\begin{array}{l}\text { Children } \\
(N=112)\end{array}$} \\
\hline & $\mathbf{M}$ & SD & $\mathbf{M}$ & SD & $\mathbf{M}$ & SD \\
\hline Age & 40.77 & 4.43 & 43.73 & 5.19 & 108 & 17.43 \\
\hline RMET & 23.82 & 4.03 & 22.67 & 3.67 & 17.81 & 3.85 \\
\hline GR task & 34.92 & 1.93 & 34.48 & 1.66 & 26.29 & 1.88 \\
\hline Educ. & 12.53 & 3.08 & 11.78 & 3.49 & & \\
\hline PPVT-s & & & & & 103.13 & 11.88 \\
\hline PPVT-r & & & & & 121.71 & 20.88 \\
\hline CPM-p & & & & & 61.20 & 25.55 \\
\hline CPM-r & & & & & 26.96 & 4.96 \\
\hline
\end{tabular}

M, mean; SD, standard deviation; RMET, global score on The Reading the Mind in the Eyes Test; GR task: score on Gender Recognition task; Educ., Years of education; PPVT$s$, standard score on Peabody Picture Vocabulary Test; PPVT-r, raw score on Peabody Picture Vocabulary Test; CMP-p, percentile scores on Raven Progressive Matrices; CMP-r, raw scores on Raven Progressive Matrices.

TABLE 2 | Partial correlations between RMET-C, CPM, and PPVT scores, controlling for children's age.

\begin{tabular}{lcc}
\hline & CPM & PPVT \\
\hline RMET-C & $0.408^{\star \star \star}$ & $0.258^{\star \star}$ \\
CPM & & $0.377^{\star \star \star}$
\end{tabular}

CPM, raw scores on Progressive Matrices; PPVT, raw score on Peabody Picture Vocabulary Test; RMET-C, global score on The Reading the Mind in the Eyes Test -Child version.

${ }^{* \star} p<0.01 ;{ }^{* \star *} p<0.001$.

TABLE 3 | Multiple regression analyses for predicting RMET-C performance.

\begin{tabular}{|c|c|c|c|c|c|}
\hline & \multicolumn{5}{|c|}{$\begin{array}{l}\text { Children's RMET-C score } \\
\text { B) }=15.784 ; R^{2}=0.305 ; p<0.0001\end{array}$} \\
\hline & $B$ & $S E$ & $\beta$ & $t$ & $p$ \\
\hline CPM & 0.291 & 0.076 & 0.387 & 3.843 & $<-0001$ \\
\hline PPVT & 0.026 & 0.020 & 0.143 & 1.294 & 0.198 \\
\hline Age & 0.023 & 0.023 & 0.106 & 1.004 & 0.318 \\
\hline
\end{tabular}

final model in bold; CMP, raw score on Progressive Matrices; PPVT, raw score on Peabody Picture Vocabulary Test.

there was no effect of sex on children's affective ToM $(F=0.934$, $p=0.336)$.

Partial correlation analysis, controlling for age, was used to investigate the association between RMET-C, PPVT-R, and CPM scores. Results yielded significant correlations between children's performance on RMET-C, PVVT-R ( $r=0.258, p=0.006)$, and CPM scores $(r=408, p<0.0001)$. Results are shown in Table 2.

To explore the extent to which PPVT-R and CPM scores predict RMET-C performance in children, a multiple regression analysis was carried out using children's PPVT-R, CPM scores and age as predictors of the children's RMET-C performance.
TABLE 4 | Partial correlations between RMET-C, mother's education, father's education, mother's performance on RMET, and father's performance on RMET, controlling for children's age.

\begin{tabular}{lcccc}
\hline & ME & FE & M-RMET & F-RMET \\
\hline RMET-C & 0.173 & 0.140 & -0.017 & 0.140 \\
\hline
\end{tabular}

ME, mothers' education; FE, fathers' education; M-RMET, global score on the Reading the Mind in the Eyes Test-Adult version reported by mothers; F-RMET, global score on the Reading the Mind in the Eyes Test-Adult version reported by fathers; RMET-C, global score on the Reading the Mind in the Eyes Test-Child version.

The final model, shown in Table 3, accounts for approximately $30 \%$ of the variance in children's RMET-C score. Specifically, only the CPM score predicted children's RMET-C score $(t=3.843, p$ $<0.0001)$.

With regard to the effect of the family's influence on affective ToM, partialled correlation analysis, controlling for children's age, was conducted to investigate the association of the children's affective ToM with parents' education and parents' performance on RMET scores. Results yielded no significant correlation, as shown in Table 4.

Finally, the effect of having older siblings on affective ToM was investigated using an analysis of covariance with age as the covariate. Forty-six of 112 children had older siblings. No significant effect with regard to older siblings was found $(F=$ $0.200, p=0.655)$.

\section{DISCUSSION}

Preliminary results found that the data produced robust variability in distribution, thus supporting the notion that RMET is not susceptible to the ceiling effect in middle childhood (BaronCohen et al., 2001b). Internal consistency for RMET-C was less than acceptable (Devellis, 2012), replicating findings from the Italian validation study of the adult version of RMET (Vellante et al., 2013), and from other studies on the psychometric properties of the children's version (Müller and Gmünder, 2014; Hayward and Homer, 2017), thus raising further questions regarding its unidimensionality. Positive and negative affect subscales were previously hypothesized (for a review, Hudson et al., 2020).

In line with some previous studies (e.g., Chapman et al., 2006; Misailidi, 2018), a significant effect of age was found on children's performance. No effect of sex was found, even when controlling for age, thus replicating Warnell and Redcay (2019) findings in middle childhood.

Significant positive correlations were found between RMET$\mathrm{C}$ performance, fluid intelligence, and receptive language. A significant association between fluid intelligence and RMET-C performance had also previously been found by two studies (Ibanez et al., 2013; Levy and Milgram, 2016). To our knowledge, only two studies on school-aged children (Lecciso et al., 2013; Peterson et al., 2015) used PPVT-R to investigate the association between receptive language and RMET performance. Lecciso et al. (2013) found that receptive language predicted RMET performance, whereas Peterson et al. (2015) did not find any 
significant associations. In our study, a regression analysis using CPM, PPVT-R, and age as predictors of the children's RMETC performance revealed that fluid intelligence was the only predictor, and that the model accounts for approximately $30 \%$ of the variance. It is noteworthy to point out that the effect of fluid intelligence was observed above and beyond the effect of age. Findings from the current study show that the effect of fluid intelligence on RMET performance, previously reported in a sample of secondary school students (Ibanez et al., 2013) and in two non-clinical adult samples (Bates and Gupta, 2017; Meinhardt-Injac et al., 2020), is also substantial in middle childhood. The effect of fluid intelligence on RMET performance may be related to the fact that RMET involves facial processing, which is also associated with fluid intelligence (Wilhelm et al., 2010), and that both fluid intelligence and social cognition engage the frontal lobe (Roca et al., 2010).

In the current study no family influence was found on children's RMET performance: neither parental education nor the presence of older siblings had an effect on children's scores on RMET. Interestingly, no correlation has ever been found between parents' and children's RMET performance either. A vast array of studies showed that maternal mentalization had a significant effect on children's mentalizing abilities (e.g., Meins et al., 2002, 2003; Ensink et al., 2015; Rosso et al., 2015; Scopesi et al., 2015; Rosso and Airaldi, 2016), and the only previous study investigating the association between mothers' and children's RMET performance (Lecciso et al., 2013) reported a significant correlation in a sample of hearing mothers and deaf children, whereas the association was not found in the hearing dyads. However, unlike our study, Lecciso et al. used a composite ToM index combining RMET and Recognition of Faux Pas (FPT-C; Baron-Cohen et al., 1999), thus findings are not fully comparable. The absence of association between parents' and children's RMET performance observed in our study raises further questions about the diagnostic meaning of the RMET scores. Fonagy and Bateman (2019) reported that both high and low scores on RMET might suggest mentalizing deficits, thereby signaling, respectively, hypermentalizing and hypomentalizing. In fact, a number of studies (e.g., Dinsdale and Crespi, 2013) showed that individuals suffering from Borderline Personality Disorder (BPD) outperformed non-clinical individuals on RMET because of their increased proneness to focus on external

\section{REFERENCES}

Allen, J. G. (2003). Mentalizing. Bull. Menn. Clin. 67, 91-112. doi: 10.1521/bumc.67.2.91.23440

Baker, C. A., Peterson, E., Pulos, S., and Kirkland, R. A. (2014). Eyes and IQ: a meta-analysis of the relationship between intelligence and "Reading the Mind in the Eyes." Intelligence 44, 78-92. doi: 10.1016/j.intell.2014.03.001

Baribeau, D. A., Doyle-Thomas, K. A. R., Dupuis, A., Iaboni, A., Crosbie, J., McGinn, H., et al. (2015). Examining and comparing social perception abilities across childhood-onset neurodevelopmental disorders. J. Am. Acad. Child Adol. Psychiatry 54, 479-486. doi: 10.1016/j.jaac.2015.03.016

Baron-Cohen, S., Bowen, D. C., Holt, R. J., Allison, C., Auyeung, B., Lombardo, M. V., et al. (2015). The "Reading the Mind in the Eyes" test: complete absence features that, in the absence of genuine reflective mentalizing, makes them highly vulnerable in social contexts, generating high interpersonal hypersensitivity. In line with Fonagy and Bateman (2019), it could be argued that the absence of association between parents' and children's RMET performance emerging from our study might be attributable to a non-univocal interpretation of RMET scores, therefore, low scores, like high ones might indicate mentalizing deficits.

On the whole, results from the current study offer some support to the hypothesis proposed by Mary et al. (2016) that RMET-C is not a "pure" ToM task. Specifically, findings from the current study highlight the effect of fluid intelligence on RMET performance, an effect that should be taken into account when RMET is used both in research and in the clinical setting.

\section{DATA AVAILABILITY STATEMENT}

The raw data supporting the conclusions of this article will be made available by the authors, without undue reservation.

\section{ETHICS STATEMENT}

Ethical review and approval was not required for the study on human participants in accordance with the local legislation and institutional requirements. Written informed consent to participate in this study was provided by the participants' legal guardian/next of kin.

\section{AUTHOR CONTRIBUTIONS}

ARo designed the study, performed the statistical analyses, and wrote the article. ARi contributed to the search for references, coordinated data collection and scoring, and contributed to the final version. Both authors contributed to the article and approved the submitted version.

\section{ACKNOWLEDGMENTS}

We are grateful to the children and their parents who kindly took part in the study, as well as the pediatricians who agreed to collaborate in this research. of typical sex difference in $\sim 400$ men and women with autism. PLoS ONE 10:e0136521. doi: 10.1371/journal.pone.0136521

Baron-Cohen, S., Jolliffe, T., Mortimore, C., and Robertson, M. (1997). Another advanced test of theory of mind: evidence from very high functioning adults with autism or Asperger syndrome. J. Child Psychol. Psychiatry 38, 813-822.

Baron-Cohen, S., O'Riordan, M., Stone, V., Jones, R., and Plaisted, K. (1999). Recognition of faux pas by normally developing children with Asperger syndrome or high-functioning autism. J. Aut. Dev. Disord. 29, 407-418. doi: 10.1023/A:1023035012436

Baron-Cohen, S., Wheelwright, S., Hill, J., Raste, Y., and Plumb, I. (2001a). The "Reading the Mind in the Eyes" Test revised version: A study with normal adults, and adults with Asperger syndrome or high-functioning autism. J. Child Psychiatry Psychiatry 42, 241-252. doi: 10.1111/1469-7610.00715 
Baron-Cohen, S., Wheelwright, S., Spong, A., Scahill, V., and Lawson, J. (2001b). Are intuitive physics and intuitive psychology independent? A test with children with Asperger syndrome. J. Dev. Learn. Disord. 5, 47-78.

Bartsch, K., and Wellman, H. M. (1995). Children Talk About the Mind. Oxford: Oxford University Press.

Bates, T. C., and Gupta, S. (2017). Smart groups of smart people: Evidence for IQ as the origin of collective intelligence in the performance of human groups. Intelligence 60, 46-56. doi: 10.1016/j.intell.2016.11.004

Belacchi, C., Scalisi, T. G., Cannoni, E., and Cornoldi, C. (2008). Manuale CPM. Colored Progressive Matrices. Standardizzazione italiana. Firenze: Giunti O.S. Organizzazioni Speciali.

Carey, J. M., and Cassels, T. G. (2013). Comparing two forms of a childhood perspective-taking measure using CFA and IRT. Psychol. Assess. 25, 879-892. doi: 10.1037/a0032641

Carroll, J. M., and Yung, C. K. (2006). Sex and discipline differences in empathising, systemising and autistic symptomatology: evidence from a student population. J. Aut. Dev. Disord. 36, 949-957. doi: 10.1007/s10803-006-0127-9

Chapman, E., Baron-Cohen, S., and Auyeung, B. (2006). Fetal testosterone and empathy: evidence from the Empathy Quotient (EQ) and the "Reading the Mind in the Eyes" test. Soc. Neurosci. 1, 135-148. doi: 10.1080/17470910600992239

Dehning, S., Girma, E., Gasperi, S., Meyer, S., Tesfaye, M., and Siebeck, M. (2012). Comparative cross-sectional study of empathy among first year and final year medical students in Jimma University, Ethiopia: Steady state of the heart and opening of the eyes. BMC Med. Educ. 12:34. doi: 10.1186/1472-6920-12-34

Devellis, R. (2012). Scale Development Theory and Applications. New York, NY: Sage Publications.

Dinsdale, N., and Crespi, B. J. (2013). The borderline empathy paradox: evidence and conceptual models for empathic enhancements in borderline personality disorder. J. Person. Disord. 27, 172-195. doi: 10.1521/pedi_2012_26_071

Dunn, L. M., and Dunn, L. M. (1981). Peabody Picture Vocabulary Test-Revised. Circle Pines, MN: AGS Publishing.

Durdiaková, J., Celec, P., Laznibatová, J., Minárik, G., Lakatošová, S., Kubranská, A., et al. (2015). Differences in salivary testosterone, digit ratio and empathy between intellectually gifted and control boys. Intelligence 48, 76-84. doi: 10.1016/j.intell.2014.11.002

Ensink, K., Normandin, L., Target, M., Fonagy, P., Sabourin, S., and Berthelot, N. (2015). Mentalization in children and mothers in the context of trauma: an initial study of the validity of the Child Reflective Functioning Scale. Br. J. Dev. Psychol. 33, 203-217. doi: 10.1111/bjdp.12074

Fonagy, P., and Bateman, A. (2019). "Introduction," in: Handbook of Mentalizing in Mental Health Practice, eds A. Bateman, and P. Fonagy. Washington, DC: American Psychiatric Association Publishing, 3-20.

Fonagy, P., and Target, M. (2005). Commentary: bridging the transmission gap: an end to an important mystery of attachment research? Attach. Hum. Dev. 7:333-343. doi: 10.1080/14616730500269278

Fossati, A., Feeney, J., Maffei, C., and Borroni, S. (2014). Thinking about feelings: affective state mentalization, attachment styles, and borderline personality disorder features among Italian nonclinical adolescents. Psychoanal. Psychol. 31, 41-67. doi: 10.1037/a0033960

Gallant, C. M. M., Lavis, L., and Mahy, C. E. V. (2020). Developing an understanding of others' emotional states: Relations among affective theory of mind and empathy measures in early childhood. Br. J. Dev. Psychol. 38, 151-166. doi: 10.1111/bjdp.12322

George, D., and Mallery, M. (2010). SPSS for Windows Step by Step: A Simple Guide and Reference, 17.0 update (10a ed.) Boston: Pearson.

Girli, A. (2014). Psychometric properties of the Turkish child and adult form of "Reading the Mind in the Eyes Test." Psychology 5, 1321-1337. doi: 10.4236/psych.2014.511143

Ha, C., Sharp, C., Ensink, K., Fonagy, P., and Cirino, P. (2013). The measurement of reflective function in adolescents with and without borderline traits. J. Adol. 36, 1215-1223. doi: 10.1016/j.adolescence.2013.09.008

Hallerbäck, M. U., Lugnegård, T., Hjärthag, F., and Gillberg, C. (2009). The Reading the Mind in the Eyes Test: test-retest reliability of a Swedish version. Cogn. Neuropsych. 14, 127-143. doi: 10.1080/13546800902901518

Happé, F. G. E. (1994). An advanced test of theory of mind: understanding of story characters' thoughts and feelings by able autistic, mentally handicapped, and normal children and adults. J. Autism Dev. Disord. 24, 129-154. doi: $10.1007 / \mathrm{BF} 02172093$

Harkness, K. L., Jacobson, J. A., Duong, D., Sabbagh, M. A. (2010). Mental state decoding in past major depression: effect of sad versus happy mood induction. Cogn. Emot. 24, 497-513. doi: 10.1080/02699930902750249

Hayward, E. O., and Homer, B. D. (2017). Reliability and validity of advanced theory-of-mind measures in middle childhood and adolescence. Br. J. Dev. Psychol. 35, 454-462. doi: 10.1111/bjdp.12186

Hudson, C. C., Shamblaw, A. L., Harkness, K. L., and Sabbagh, M. A. (2020). Valence in the reading the mind in the eyes task. Psychol. Assess. 32, 623-634. doi: $10.1037 /$ pas0000818

Hughes, C., and Devine, R. T. (2017). "Family influences on theory of mind: A review," in Theory of Mind Development in Context, eds V. Slaughter and M. de Rosnay (London: Routledge/Taylor and Francis Group), 41-56.

Ibanez, A., Huepe, D., Gempp,. R., Gutiérrez, V., Rivera-Rei, A., and Toledo,. M. I. (2013). Empathy, sex and fluid intelligence as predictors of theory of mind. Personal. Indiv. Diff. 54, 616-621. doi: 10.1016/j.paid.2012.11.022

Kirkland, R. A., Peterson, E., Baker, C. A., Miller, S., and Pulos, S. (2013). Metaanalysis reveals adult female superiority in "Reading the Mind in the Eyes" Test. North Am. J. Psych. 15, 121-146.

Lawrence, E. J., Shaw, P., Baker, D., Baron-Cohen, S., and David, A. S. (2004). Measuring empathy: reliability and validity of the empathy quotient. Psychol. Med. 34, 911-919. doi: 10.1017/S0033291703001624

Lecce, S., Demicheli, P., Zocchi, S., and Palladino, P. (2015). The origins of children's metamemory: The role of theory of mind. J Experimental Child Psychology 131, 56-72. doi: 10.1016/j.jecp.2014.11.005

Lecciso, F., Petrocchi, S., and Marchetti, A. (2013). Hearing mothers and oral deaf children: an atypical relational context for theory of mind. Europ. J. Psychol. Educ. 28, 903-922. doi: 10.1007/s10212-012-0146-1

Levy, N. K., and Milgram, N. (2016). Cognitive contributions to theory of mind ability in children with a traumatic head injury. Child Neuropsychol. 22, 177-196. doi: 10.1080/09297049.2014.985642

Liverta Sempio, O., Marchetti, A., and Castelli, I. (2003). Test degli Occhi-versione bambini (TOB)[Eyes test- Children version] Unità di Ricerca sulla Teoria della Mente, Dipartimento di Psicologia. Milano: Università Cattolica.

Longobardi, E., Spataro, P., D'Alessandro, M., and Cerutti, R. (2017). Temperament dimensions in preschool children: links with cognitive and affective theory of mind. Early Educ. Dev. 28, 377-395. doi: 10.1080/10409289.2016.1238673

Luyten, P., Malcorps, S., Fonagy, P., and Ensink, K. (2019). "Assessment of mentalizing," in Handbook of Mentalizing in Mental Health Practice, eds A. Bateman, and P. Fonagy (Washington, DC: American Psychiatric Association Publishing), 37-62.

Mary, A., Slama, H., Mousty, P., Massat, I., Capiau, T., Drabs, V., et al. (2016). Executive and attentional contributions to Theory of Mind deficit in attention deficit/hyperactivity disorder (ADHD). Child Neuropsychol. 22, 345-365. doi: 10.1080/09297049.2015.1012491

Meinhardt-Injac, B., Daum, M. M., and Meinhardt, G. (2020). Theory of mind development from adolescence to adulthood: testing the twocomponent model. Br. J. Dev. Psychol. 38, 289-303. doi: 10.1111/bjdp. 12320

Meins, E., Fernyhough, C., Wainwright, R., Clark-Carter, D., Das Gupta, M., Fradley, E., et al. (2003). Pathways to understanding mind: construct validity and predictive validity of maternal mind-mindedness. Child Dev. 74, 1194-1211. doi: 10.1111/1467-8624.00601

Meins, E., Fernyhough, C., Wainwright, R., Das Gupta, M., Fradley, E., and Tuckey, M. (2002). Maternal mind-mindedness and attachment security as predictors of theory of mind understanding. Child Dev. 73, 1715-1726. doi: 10.1111/1467-8624.00501

Misailidi, P. (2018). Individual differences in children's understanding of guilt: links with theory of mind. J. Genet. Psychol. 179, 219-229. doi: 10.1080/00221325.2018.1474848

Müller, C. M., and Gmünder, L. (2014). An evaluation of the "reading the mind in the eyes-test" with seventh to ninth graders. J. Mental Health Res. Intell. Disabil. 7, 34-44. doi: 10.1080/19315864.2012. 714055

Oakley, B. F. M., Brewer, R., Bird, G., and Catmur, C. (2016). Theory of mind is not theory of emotion: a cautionary note on the Reading 
the Mind in the Eyes Test. J. Abnorm. Psychol. 125, 818-823. doi: 10.1037/abn0000182.supp (Supplemental)

Olderbak, S., Wilhelm, O., Olaru, G., Geiger, M., Brenneman, M. W., and Roberts, R. D. (2015). A psychometric analysis of the reading the mind in the eyes test: Toward a brief form for research and applied settings. Front. Psychol. 6:1503. doi: 10.3389/fpsyg.2015.01503

Peñuelas-Calvo, I., Sareen, A., Sevilla-Llewellyn-Jones, J., and Fernández-Berrocal, P. (2019). The "Reading the Mind in the Eyes" Test in Autism-Spectrum Disorders comparison with healthy controls: a systematic review and metaanalysis. J. Autism Dev. Disord. 49, 1048-1061. doi: 10.1007/s10803-018-3814-4

Peterson, C. C., Slaughter, V., and Brownell, C. (2015). Children with autism spectrum disorder are skilled at reading emotion body language. J. Exp. Child Psychol. 139, 35-50. doi: 10.1016/j.jecp.2015.04.012

Ragsdale, G., and Foley, R. A. (2011). A maternal influence on reading the mind in the eyes mediated by executive function: Differential parental influences on full and half-siblings. PLoS ONE 6:e23236. doi: 10.1371/journal.pone.0023236

Raven, J., Court, J. H., and e Raven, J. C. (1998). Raven Manual, Section 1 (General overview) and Section 2 (Colored Progressive Matrices). Oxford, UK: Oxford Psychologist Press

Roca, M., Parr, A., Thompson, R., Woolgar, A., Torralva, T., Antoun, N., et al. (2010). Executive function and fluid intelligence after frontal lobe lesions. Brain J. Neurol. 133, 234-247. doi: 10.1093/brain/awp269

Rosso, A. M., and Airaldi, C. (2016). Intergenerational transmission of reflective functioning. Front. Psychol. 7:1903. doi: 10.3389/fpsyg.2016.01903

Rosso, A. M., Viterbori, P., and Scopesi, A. M. (2015). Are maternal reflective functioning and attachment security associated with preadolescent mentalization? Front. Psychol. 6, 1-12. doi: 10.3389/fpsyg.2015.01134

Rutherford, H. J. V., Wareham, J. D., Vrouva, I., Mayes, L. C., Fonagy, P., and Potenza, M. N. (2012). Sex differences moderate the relationship between adolescent language and mentalization. Personal. Disord. Theory Res. Treat. 3, 393-405. doi: 10.1037/a0028938

Sabbagh, M. A., and Seamans, E. L. (2008). Intergenerational transmission of theory-of-mind. Dev. Sci. 11, 354-360. doi: 10.1111/j.1467-7687.2008.00680.x

Schurz, M., Radua, J., Aichhorn, M., Richlan, F., and Perner, J. (2014). Fractionating theory of mind: a meta-analysis of functional brain imaging studies. Neurosci. Biobehav. Rev. 42, 9-34. doi: 10.1016/j.neubiorev.2014. 01.009

Scopesi, A. M., Rosso, A. M., Viterbori, P., and Panchieri, E. (2015). Mentalizing abilities in preadolescents' and their mothers' autobiographical narratives. $J$. Early Adolesc. 35, 467-483.doi: 10.1177/0272431614535091

Serafin, M., and Surian, L. (2004). Il Test degli Occhi: Uno strumento per valutare la "teoria della mente" = The Eyes Test: an instrument for evaluating the "theory of mind." Giorn. Ital. Psicol. 31, 839-860.
Sharp, C. (2008). Theory of Mind and conduct problems in children: deficits in reading the "emotions of the eyes." Cogn. Emot. 22, 1149-1158. doi: 10.1080/02699930701667586

Stella, G., Pizzioli, C., and Tressoldi, P. (2000). Peabody Picture Vocabulary Test-Revised (PPVT-R). Adattamento italiano e standardizzazione. Torino: Omega Edizioni.

Stevens, S. A., Clairman, H., Nash, K., and Rovet, J. (2017). Social perception in children with fetal alcohol spectrum disorder. Child Neuropsychol. 23, 980-993. doi: 10.1080/09297049.2016.1246657

Vellante, M., Baron-Cohen, S., Melis, M., Marrone, M., Petretto, D. R., Masala, C., et al. (2013). The "Reading the Mind in the Eyes" test: systematic review of psychometric properties and a validation study in Italy. Cogn. Neuropsych. 18, 326-354. doi: 10.1080/13546805.2012.721728

Vogindroukas, I., Chelas, E.-N., and Petridis, N. E. (2014). Reading the Mind in the Eyes Test (Children's Version): a comparison study between children with typical development, children with high-functioning autism and typically developed adults. Folia Phoniatrica et Logopaedica 66, 18-24. doi: $10.1159 / 000363697$

Voracek, M., and Dressler, S. G. (2006). Lack of correlation between digit ratio (2D:4D) and Baron-Cohen's "Reading the Mind in the Eyes" test, empathy, systemising, and autism-spectrum quotients in a general population sample. Personal. Individ. Differ. 41, 1481-1491. doi: 10.1016/j.paid.2006.06.009

Warnell, K. R., and Redcay, E. (2019). Minimal coherence among varied theory of mind measures in childhood and adulthood. Cognition 191. doi: 10.1016/j.cognition.2019.06.009

Wilhelm, O., Herzmann, G., Kunina, O., Danthiir, V., Schacht, A., and Sommer, W. (2010). Individual differences in perceiving and recognizing facesOne element of social cognition. J. Person. Soc. Psychol. 99, 530-548. doi: $10.1037 / \mathrm{a} 0019972$

Wimmer, H., and Perner, J. (1983). Beliefs about beliefs: representation and constraining function of wrong beliefs in young children's understanding of deception. Cognition 13, 103-128. doi: 10.1016/0010-0277(83)90004-5

Conflict of Interest: The authors declare that the research was conducted in the absence of any commercial or financial relationships that could be construed as a potential conflict of interest.

Copyright (c) 2020 Rosso and Riolfo. This is an open-access article distributed under the terms of the Creative Commons Attribution License (CC BY). The use, distribution or reproduction in other forums is permitted, provided the original author(s) and the copyright owner(s) are credited and that the original publication in this journal is cited, in accordance with accepted academic practice. No use, distribution or reproduction is permitted which does not comply with these terms. 